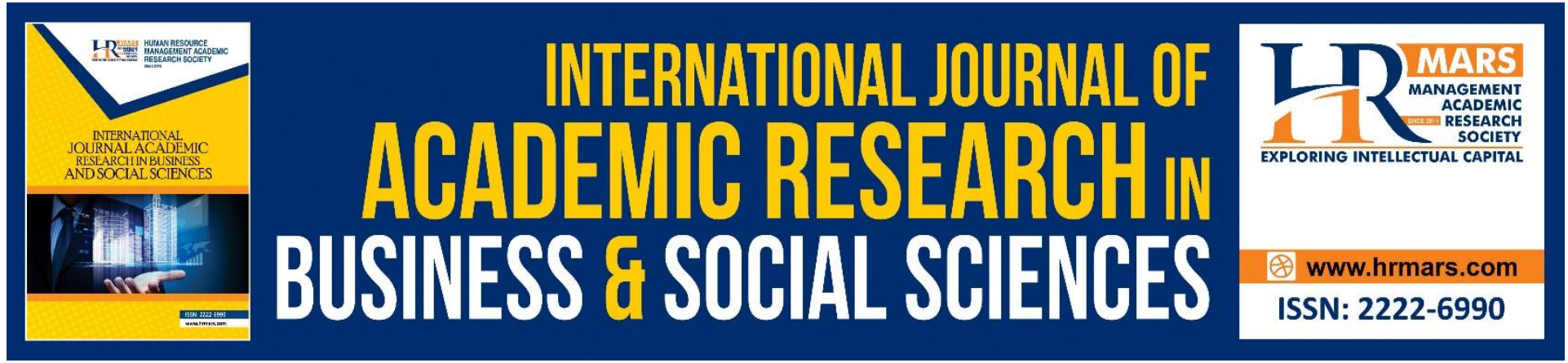

\title{
High-Risk Situations of Inclinations to Relapse among Former Drug Addicts: A Descriptive Analysis
}

\author{
Asbah Razali, Zainal Madon
}

To Link this Article: http://dx.doi.org/10.6007/IJARBSS/v11-i6/10000

DOI:10.6007/IJARBSS/v11-i6/10000

Received: 17 April 2021, Revised: 20 May 2021, Accepted: 02 June 2021

Published Online: 21 June 2021

In-Text Citation: (Razali \& Madon, 2021)

To Cite this Article: Razali, A., \& Madon, Z. (2021). High-Risk Situations of Inclinations to Relapse among Former Drug Addicts: A Descriptive Analysis. International Journal of Academic Research in Business and Social Sciences, 11(6), 1140-1153.

\section{Copyright: (c) 2021 The Author(s)}

Published by Human Resource Management Academic Research Society (www.hrmars.com)

This article is published under the Creative Commons Attribution (CC BY 4.0) license. Anyone may reproduce, distribute, translate and create derivative works of this article (for both commercial and non-commercial purposes), subject to full attribution to the original publication and authors. The full terms of this license may be seen at: http://creativecommons.org/licences/by/4.0/legalcode

Vol. 11, No. 6, 2021, Pg. 1140- 1153

Full Terms \& Conditions of access and use can be found at http://hrmars.com/index.php/pages/detail/publication-ethics 


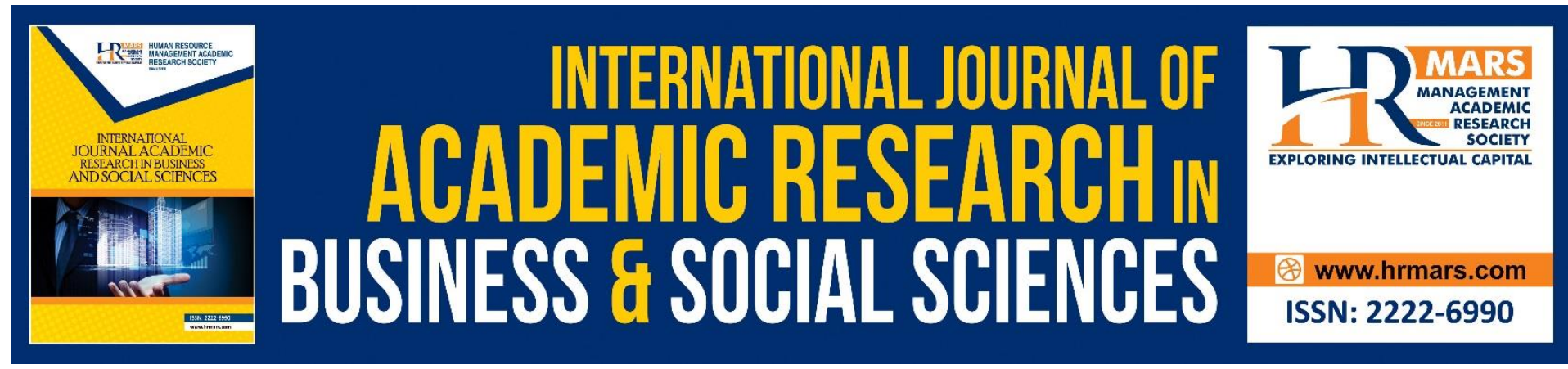

\title{
High-Risk Situations of Inclinations to Relapse among Former Drug Addicts: A Descriptive Analysis
}

\author{
Asbah Razali ${ }^{1}$, Zainal Madon² \\ ${ }^{1}$ Department of Anthropology and Sociology, Faculty of Art and Social Sciences, University of \\ Malaya, Kuala Lumpur, Malaysia. ${ }^{2}$ Department of Human Development and Family Studies, \\ Faculty of Ecology, University Putra Malaysia, Selangor, Malaysia. \\ Email: asbahrazali@um.edu.my, zainalm@upm.edu.my
}

\begin{abstract}
Although the government has carried out countless efforts to prevent relapse among drug addicts after receiving treatment, the increasing rate of relapsed addicts still remains at a worrying level. To this day, the country bears a high cost to treat and rehabilitate former drug addicts. This study aims to identify the levels of inclination of relapse based on eight high-risk situations usually faced by former addicts. This study involved 242 former drug addicts that completed the treatment and rehabilitation period, utilizing the Inventory of Drug-Taking Situations instrument (IDTS) by Annis and Martin (1985). The findings show the inclination to relapse among former addicts are at a high level for all high-risk situation dimensions. This means the participating respondents are at a high-risk of relapse. Therefore, in their efforts to combat the problem of relapse, the National Antidrug Agency (AADK) and the Cure and Care Rehabilitation Centre (CCRC) must take into account risk factors that contribute to relapse among addicts, and then adopting them as a guideline to further strengthen strategies to combat this problem in the future.
\end{abstract}

Keywords: Relapse, Addiction, Drug, High Risk Situation

\section{Introduction}

The inclination to relapse is a psychological and behavioural disorder. It is related to the addict's desire to reuse drugs after the end of their treatment and rehabilitation process (Shafiei et al., 2014). According to a report published by the Substance Abuse and Mental Health Services Administration (SAMHSA) in 2017, more than 50 per cent of drug addicts were inclined to relapse post-treatment and rehabilitation. Statistics by the National Anti-Drugs Agency (AADK) showed that in 2019, 26,260 addicts have been identified from January to December 2019. From this number, 17,506 were new addicts, while 8,754 were relapsed addicts. This number showed an increase from the previous year, where in 2018, there were 17,474 new cases and 7,793 cases of relapsed addicts. Although the government has carried multiple efforts to reduce the drug addiction problem in Malaysia, this relapse issue seemed unending. Relapse is very difficult to contain, as the number of repeat addicts increase year by year. This increase might be caused by their exposure to high-risk situations, such as 
negative emotions, physical discomfort, social pressure, interpersonal conflict, and others, post-treatment and rehabilitation. They were in high-risk situations to relapse because of the present of negative reaction and their inability to fight these urges (Tomczak, 2010). This study aims to know the background of former addicts and identify the level of inclination to relapse based on eight dimensions of high-risk situations of inclination to relapse, beginning with factors labelled as high-risk situations: negative emotions, physical discomfort, positive emotions, lack of self-control, desire for drugs, interpersonal conflict, social pressure, and peer pressure.

According to Annis and Martin (1985), negative emotions refer to negative feelings such as anger, disappointment, jealousy, guilt, depression, and boredom. When a former drug addict is located within a negative and unstable emotion, the probability to relapse increases. Addicts were easily influenced by emotion, as the concept of emotion is easily influenced by basic evaluation and environment. The same situation is related to previous studies on how negative emotions causes increase in pressure to relapse (Skitch \& Abela, 2008). When an addict feels himself in need of drugs but unable to access them, they feel physical discomfort and their bodies tremble. They then seek for drugs to alleviate the feeling of physical pain (Hartwell et al., 2012). Aside from negative emotions, even positive emotions, such as enjoyment, overconfidence, and satisfaction with life, can increase the inclination to relapse. They require positive rewards to overcome negative feelings and desires. According to Gottfredson and Hirschi (1986), lack of self-control makes someone more vulnerable to criminal behaviour, as such behaviours reward them with short-term satisfaction, and also unable to overcome stress, be impulsive, and inclined towards risk-taking. They do not require any form of motivation to commit crime, as they feel enjoyment from their actions. They also fail to consider negative effects of their actions.

In addition, other dimensions of high-risk situations include desire for drugs. This desire covers both psychological and physical desires to return to behaviours that should be avoided. The feeling and desire for drug-using allow the mind of the addict to relapse to said behaviour. From a cognitive and behavioural aspect, the inclination to relapse is a combination of enjoyment and alleviation of pain. Interpersonal conflict refers to misunderstanding or disagreement of opinions between parties due to differences in strongly-held opinions. When former addicts enter into conflict with another, they have a high-risk of reacting negatively. A study by Howell, Leyro, Hogan, Buckner and Zvolensky (2010) found when drug addicts are in a high conflict situation, the risk of relapse increases. Social pressure refers to environmental pressure that triggers the addict's desire to relapse. Social pressure covers direct and indirect pressure. For instance, the individual is offered to partake in drug-use by their friends or environment, a drug nest.

Social pressure covers societal stigma towards former drug addicts, considered as "bad people." Peer pressure refers to the situation when drug addicts reconnect with their friends who are also drug addicts. While with friends, they are most likely easily influenced, and find difficulty to resist when offered to partake (Hu, Davies, \& Kandel, 2006). To understand the inclination to relapse, Marlatt and Gordon, (1985) build a cognitive and behavioural model. Based on this model, relapsed behaviour is a long process, and does not occur suddenly. It begins as a high-risk situation as a response to expectation, urges, desiretriggering situations, skills development, and self-control. Figure 1 depicts the behavioural model of Marlatt and Gordon (1985) towards the inclination to relapse. 


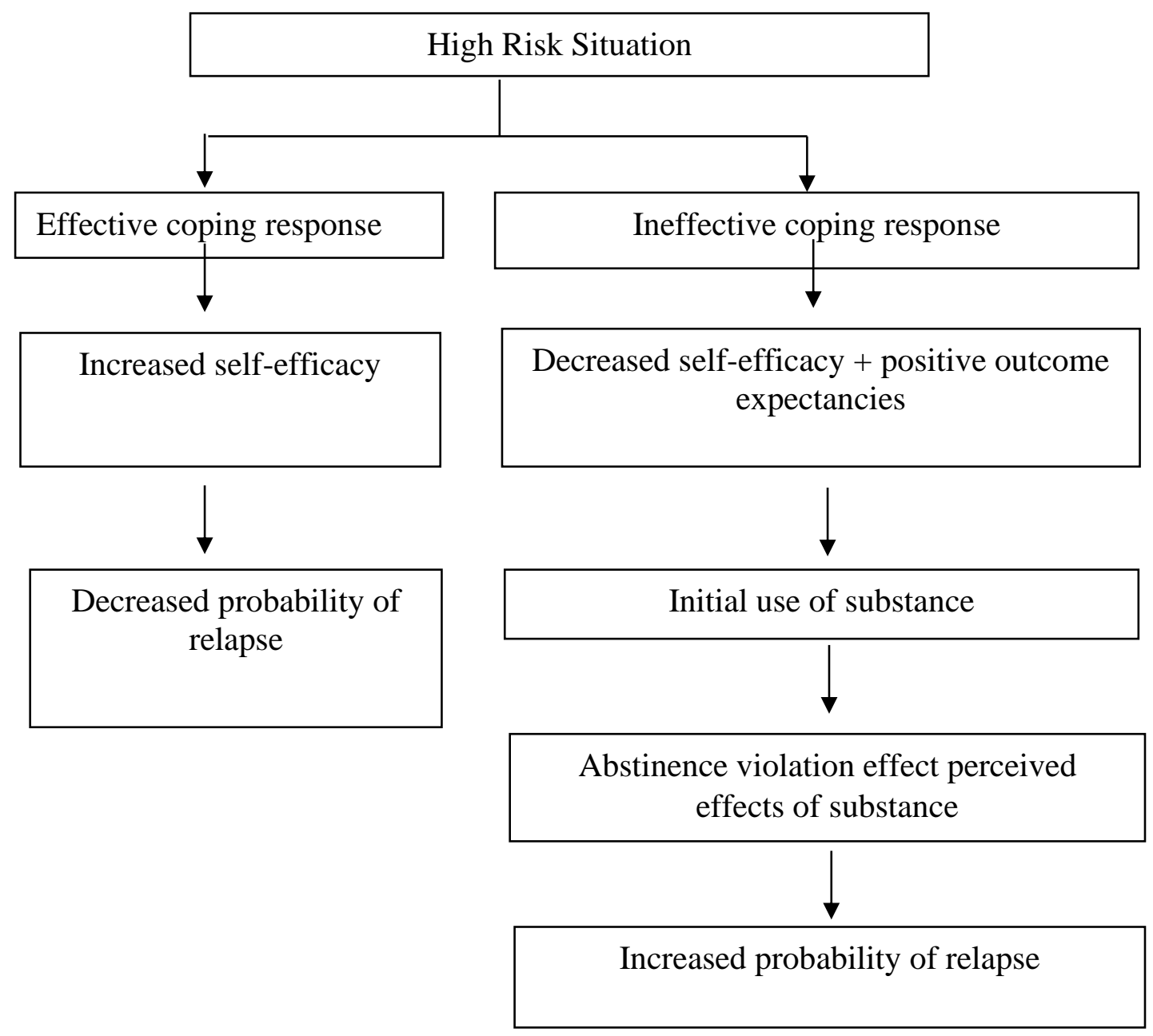

Figure 1: Model of Marlatt and Gordon (1985)

Based on Figure 1, relapsed behaviour is a long and gradual process. It begins with high-risk situations as a response to expectations, urges, desire-triggering situations, skills development, and self-control. Without the skills to manage high-risk situation pressure, the threat of relapse increase. In addition, this behavioural dimension also covers internal urges and desires to the inclination to relapse. The addict's desire weakens their motivation when they find themselves in unexpected risky situations. Meanwhile, urges are drastic feelings to relapse within the addict, and the desire is a consequence of said urges. If they have no strategy for self-control, they are easily influenced by environmental pressures, triggering the inclination to relapse. Marlatt and Gordon (1985) explains the ability of former addicts to overcome high-risk situations can prevent them from relapsing. This means their ability to assess high-risk situations (such as emotional stress) can become the basis of their behaviour, either being inclined to relapse or otherwise. It depends of their ability to manage the risk to relapse, but it can be overcome through self-efficacy, to transform the risky situation to positive expectation. This model suggests that long-term positive expectation can act as a mediator between high-risk situations and the inclination to relapse.

Annis and Martin (1985) states high-risk situations consist of eight aspects of the drug addict: negative emotion, physical discomfort, positive emotion, lack of self-control, desire for drugs, conflict, social pressure, and time pressure. In fact, drug addicts are exposed to the risk of relapse when faced with situations such as negative emotions, interpersonal conflicts 
such as disagreements, differences in opinion with family members, and facing social pressure. Table 1 shows eight high-risk situations as outlined by Annis and Martin (1985). To understand the inclination to relapse, Marlatt and Gordon (1985) build a cognitive and behavioural model to further explain the problem of inclination to relapse. In this model, Marlatt and Gordon (1985) see the inclination to relapse as a complex process, created from some high-risk situations that covers expectations, decision, physiological effects, and behaviour. High-risk situations can influence one's inclination to relapse, and affect their behaviour. According to Marlatt and Gordon (1985) the addict's rehabilitation process is too complex, as they are described as suffering from chronic disturbance, and could potentially relapse post-treatment and rehabilitation. This model covers the cognitive and behavioural aspect as developed by Marlatt and Gordon (1985) based on empirical discovery. This model is also based on a number of high-risk situations that leads drug addicts to incline to relapse.

Furthermore, other factors also lead to the inclination to relapse such as mindsets, imbalanced lifestyle, and lack of life-goals. The more risk factors faced by addicts, the higher the possibility of relapse. This cognitive and behavioural model also covers strategies and actions taken by drug addicts to identify the inclination to relapse within them. The strategies include the process of identifying high-risk situations and the skills to overcome said situations, improving self-efficacy, and rebuilding their perception to allow them to reduce the inclination to relapse risk. Marlatt and Gordon (1985) also conceded when an addict feels under pressure, their cognitive capacity is affected and influences the inclination to relapse. This means the inclination of former addicts to relapse does not occur suddenly, but a gradual process that begins with the presence of high-risk situations and environmental pressure that creates the stimuli to return to their old behaviour. In fact, based on this model, the inclination to relapse is also triggered by external and internal factors that stimulate and encourage oneself to relapse, such as interpersonal problems that trigger negative reaction, and signal towards drug-reuse. To further strengthen this model, Marlatt and Gordon (1985) built a cognitive behavioural model to assess the extent high-risk situations affect the inclination to relapse that then influence the life of former drug addicts.

Table 1: High-Risk Situations on the Inclination to Relapse

\begin{tabular}{|c|c|}
\hline \multicolumn{2}{|c|}{ High-Risk Situation on the Inclination to Relapse (Annis \& Martin, 1985) } \\
\hline $\begin{array}{l}\text { 1. Negative } \\
\text { Emotion }\end{array}$ & $\begin{array}{l}\text { Negative emotions such as anger, disappointment, sadness, jealousy, } \\
\text { depression, and others that increase the desire to use drugs }\end{array}$ \\
\hline $\begin{array}{l}\text { 2. Physical } \\
\text { Discomfort }\end{array}$ & $\begin{array}{l}\text { Physical pain that causes discomfort such as sleep problems, weight loss, } \\
\text { and headaches, increasing the desire to reuse drugs }\end{array}$ \\
\hline $\begin{array}{l}\text { 3. Positive } \\
\text { Emotion }\end{array}$ & $\begin{array}{l}\text { Positive emotions such as happiness, confidence, excitement, and } \\
\text { satisfaction that increases desire to reuse drugs }\end{array}$ \\
\hline $\begin{array}{l}\text { 4. Personal } \\
\text { Control }\end{array}$ & $\begin{array}{l}\text { Testing oneself to measure one's ability to overcome desire for drugs or } \\
\text { not }\end{array}$ \\
\hline 5. Desire & Desire for drugs makes one consider how good it is to be an addict \\
\hline 6. Conflict & Anger or conflict with others increases desire to reuse drugs \\
\hline $\begin{array}{l}\text { 7. Social } \\
\text { Pressure }\end{array}$ & Pressure from social environment increase desire to reuse drugs \\
\hline 8. Peer Pressure & Proximity to friends might influence them to relapse \\
\hline
\end{tabular}




\section{Methodology}

\section{Research Population and Location}

The study population consists of drug addicts that completed their treatment and rehabilitation at the Cure and Care Rehabilitation Centre CCRC, based on information collected from the administration in selected CCRCs. Population selection is based on the records of the treatment and rehabilitation end period in each CCRC in a period between one and six months. The study location covers all CCRCs in Peninsular Malaysia: the CCRC Sungai Besi, CCRC Bukit Mertajam, Pulau Pinang, CCRC Raub, Pahang, CCRC Tampin, Melaka CCRC Tampoi, Johor Bahru, CCRC Jeli, Kelantan, CCRC Kota Bharu, Kelantan, and CCRC Perlop, Perak. Table 2 shows the population of former drug addicts that completed treatment and rehabilitation in CCRCs in Malaysia.

Table 2: Population of Former Drug Addicts in CCRCs

\begin{tabular}{ccc}
\hline Number & Cure and Care Rehabilitation Centre (CCRC) & Total \\
\hline 1. & CCRC Sungai Besi, Kuala Lumpur & 70 \\
2. & CCRC Tampin, Melaka & 81 \\
3. & CCRC Tampoi, Johor & 75 \\
4. & CCRC Raub, Pahang & 79 \\
5. & CCRC Bukit Mertajam, Pulau Pinang & 50 \\
6. & CCRC Jeli, Kelantan & 70 \\
7. & CCRC Kota Bharu, Kelantan & 60 \\
8. & CCRC Perlop, Perak & 55 \\
\hline
\end{tabular}

\section{Sampling Technique}

This study sample was selected using cluster sampling method. Four CCRCs group according to zones which is the North, South, Central and East represent the populations in this study. Table 3 shows the four CCRCs that were selected based on cluster sampling.

Table 3: Cluster Sampling Method ( $\mathrm{N}=\mathbf{2 8 0})$

\begin{tabular}{|c|c|c|c|c|}
\hline Number & $\begin{array}{c}\text { Cure and Care } \\
\text { Rehabilitation Centre } \\
\text { (CCRC) }\end{array}$ & $\begin{array}{c}\text { Total } \\
\text { Sampling }\end{array}$ & $\begin{array}{c}\text { Total } \\
\text { Responden }\end{array}$ & $\begin{array}{l}\text { Response } \\
\text { Percentage }\end{array}$ \\
\hline 1. & $\begin{array}{l}\text { CCRC Sungai Besi, Kuala } \\
\text { Lumpur }\end{array}$ & 70 & 61 & $87.1 \%$ \\
\hline 2. & CCRC Tampoi, Johor Bahru & 75 & 63 & $84.0 \%$ \\
\hline 3. & $\begin{array}{c}\text { CCRC Bukit Mertajam, } \\
\text { Pulau Pinang }\end{array}$ & 65 & 59 & $90.7 \%$ \\
\hline \multirow[t]{2}{*}{4.} & CCRC Kota Bharu, Kelantan & 70 & 59 & $84.3 \%$ \\
\hline & Total & $\mathbf{N}=\mathbf{2 8 0}$ & $n=242$ & \\
\hline
\end{tabular}

\section{Measurement Tool and Evaluation Method}

Measurement tool refers to questionnaires used as variables in this study, and evaluation method is the method to get the values of each measurement item. In this study, the 
questionnaire Inventory of Drug-Taking Situations, (IDTS) by Annis and Martin (1985) is utilised. The IDTS instrument contains 50 question items covering eight high-risk situations: negative emotions ( 10 items), physical discomfort ( 5 items), positive emotions ( 5 items), selfcontrol ( 5 items), desire for drugs (5 items), interpersonal conflict (10 items), social pressure (5 items), and peer pressure (5 items). The measurement instrument for the inclination to relapse is a five-point likert scale of $1=$ strongly agree $2=$ agree $3=$ not sure $4=$ disagree $5=$ strongly disagree. Negative questions are re-recorded as $1=$ strongly disagree $2=$ disagree $3=$ not sure $4=$ agree, and $5=$ strongly agree. The total score is obtained through adding the scores of each section. The highest score means the level of inclination is high. The low score distribution shows low inclination to relapse. Table 4 shows the item division according to the eight dimensions of inclination to relapse.

Table 4: Eight Dimensions of Inclination to Relapse

\begin{tabular}{ccc}
\hline Dimension & Item & Total \\
\hline Negative Emotion & $1,10,11,20,21,30,31,40,41,50$ & 10 \\
Physical Discomfort & $2,12,22,32,42$ & 5 \\
Positive Emotion & $3,13,23,33,43$ & 5 \\
Personal Control & $4,14,24,34,44$ & 5 \\
Desire & $5,15,25,35,45$ & 5 \\
Conflict & $6,7,16,17,26,27,36,37,46,47$ & 10 \\
Social Pressure & $8,18,28,38,48$ & 5 \\
Peer Pressure & $9,19,29,39,49$ & 5 \\
\hline
\end{tabular}

Examples of items used for relapse tendency instruments are as follows:-

(i) Negative Emotion

"I feel lonely"

"I feel depressed"

(ii) Physical Discomfort

"I have a headache"

"I want to lose weight"

(iii) Positive Emotion

"I feel confident"

"I feel happy"

(iv) Personal Control

"I am able to control myself from taking drugs again"

"I want to prove that drugs are not a big problem in me"

(v) Desire

(vi) Conflict

"I always remember to take drugs"

"I can't help but take drugs"

"I feel uncomfortable with someone's presence"

"I can't express my feelings to someone"

(vii) Social Pressure

"I was around people taking drugs"

"I was pressured to take drugs again" 


\section{(xi) Peer Pressure}

"I am always with friends who take drugs"

"I will take drugs when with my friends"

\section{Results and Discussion}

\section{Background of Former Drug Addicts}

Table 5 : Background of Former Drug Addicts

\begin{tabular}{lcc}
\hline Background & Frequency & Percentages \\
\hline Age & & \\
\hline 15 years & 4 & 1.7 \\
$16-25$ years & 134 & 55.3 \\
$26-39$ years & 103 & 42.6 \\
39 and above & 1 & 0.4 \\
\hline
\end{tabular}

\section{Ethnicity}

\begin{tabular}{lcc}
\hline Malay & 202 & 83.4 \\
Indian & 21 & 8.7 \\
Chinese & 19 & 7.9 \\
\hline
\end{tabular}

Marital Status

\begin{tabular}{lcc}
\hline Unmarried & 111 & 45.9 \\
Married & 106 & 43.8 \\
Divorced & 25 & 10.3 \\
\hline
\end{tabular}

\section{Education Level}

\begin{tabular}{lcc} 
No Education & 19 & 7.9 \\
Primary School & 33 & 13.9 \\
Lower Secondary & 96 & 39.7 \\
$\begin{array}{l}\text { Assessment (PMR) } \\
\text { Malaysian Certificate of }\end{array}$ & 76 & 31.4 \\
$\begin{array}{l}\text { Education (SPM) } \\
\text { Skill Certificate }\end{array}$ & 18 & 7.4 \\
\hline
\end{tabular}

\section{Employment status}

\begin{tabular}{lcc}
\hline Part-time employees & 41 & 16.9 \\
Studying & 5 & 2.0 \\
Permanent employment & 51 & 21.2 \\
Self-employed & 72 & 29.8 \\
Unemployed & 73 & 30.2 \\
\hline
\end{tabular}

Table 5 shows the background summary of former drug addicts. The respondent background information consists of age, ethnicity, marital status, education level and employment status. This background information can explain the respondent profile. Based on collected data, four respondents (1.7\%) are aged 15 years and below, 134 respondents (55.3\%) are aged 16-25 years, 103 respondents (42.6\%) are aged $26-39$ years, and only one respondent (4\%) is aged 
39 years and above. The majority of former drug addicts involved in this study are aged 16-25 years. This means the majority of former drug addicts in this study are youths between the age of 16 and 25 years. Based on chronology of one's life development, in the early 20s, they are in transition from adolescence to youth. At this age, one's involvement in drug problems is a process that begins with dabbling, but the pleasure from the experience leads to repeat abuse. This is recognised by previous studies by the United Nations Drug Control (UNDCP) in 2010 , which found $3.3 \%$ to $4.1 \%$ of the global drug-addict population are adolescents aged 16- 25 years, meaning this group is the largest participant of drug abuse, and vulnerable to the risk of relapse.

Ethnicity-wise, as shown in Table 5, most respondents are Malays, or 202 people (83.4\%), followed by Indians, or 21 people (8.7\%). The rest are Chinese, or 19 people (7.9\%). The research findings show most former addicts are Malays. This is recognised by a report by the National Anti-Drug Agency (AADK) in 2013, which found Malays as the most identified group involved in drug abuse every year. This means Malay-Muslims are most involved in drug problems. For marital status, 111 people (45.9\%) are unmarried, while 106 people (43.8\%) are married. The remaining $25(10.3 \%)$ are unmarried (divorced). This means most respondents are not married. In education level, results found 19 respondents (7.9\%) have no education, 33 people (13.9\%) have a Primary School Achievement Test (Ujian Penilaian Sekolah Rendah, UPSR) certificate, 96 people (39.7\%) have a Lower Secondary Assessment (Penilaian Menengah Rendah, PMR) certificate, 76 people (31.4\%) have a Malaysian Certificate of Education (Sijil Pelajaran Malaysia, SPM) certificate, and the remaining 18 people (7.4\%) have a Skills Certificate (Sijil Kemahiran). Based on this explanation, it could be concluded that most respondents have an education level at the PMR and lower stage. This means most respondents drop out of school at a very young age. In the occupation context, 41 respondents (16.9\%) are part-time employees, five respondents (2\%) are still studying, 51 people $(21.1 \%)$ have permanent employment, 72 people $(29.8 \%)$ are self-employed while the remaining 73 respondents $(30.2 \%)$ are unemployed. This is most likely caused by their low education level. 73 respondents (30.2\%) earn an income of RM500 and below, 61 respondents (25.2\%) earn between RM500 and RM1000 a month, 24 respondents (9.9\%) earn between RM1000 and RM1500 a month, 28 respondents (11.6\%) earn RM1500 and above a month, while the remaining 56 respondents (23.1\%) are unemployed. Low income or socioeconomic status indirectly affects the inclination to relapse (Muldoon \& Lowe, 2012). To know the level of inclination to relapse based on the eight dimensions, researchers have divided the inclination to relapse variables into three stages: low, medium, and high. 
Table 6: Level of Inclination to Relapse Among Former Drug Addicts

\begin{tabular}{|c|c|c|c|c|}
\hline Inclination to Relapse & Frequency & Percentage & Mean & $\begin{array}{l}\text { Sisihan } \\
\text { Piawai }\end{array}$ \\
\hline \multicolumn{5}{|l|}{ Negative Emotion } \\
\hline Low (1.00 - 2.33) & 53 & 21.9 & 3.70 & .303 \\
\hline Medium (2.34 - 3.66) & 136 & 56.2 & & \\
\hline High (3.67 - 5.00) & 53 & 21.9 & & \\
\hline \multicolumn{5}{|l|}{ Physical Discomfort } \\
\hline Low (1.00 - 2.33) & 52 & 21.5 & 3.81 & .392 \\
\hline Medium (2.34 - 3.66) & 138 & 57.0 & & \\
\hline High (3.67 - 5.00) & 52 & 21.5 & & \\
\hline \multicolumn{5}{|l|}{ Positive Emotion } \\
\hline Low (1.00 - 2.33) & 29 & 12.0 & 3.74 & .379 \\
\hline Medium (2.34 - 3.66) & 168 & 69.4 & & \\
\hline High (3.67 - 5.00) & 45 & 18.6 & & \\
\hline \multicolumn{5}{|l|}{ Personal Control } \\
\hline Low (1.00 - 2.33) & 40 & 16.5 & 3.70 & .387 \\
\hline Medium (2.34 - 3.66) & 131 & 54.1 & & \\
\hline High (3.67 - 5.00) & 71 & 29.4 & & \\
\hline \multicolumn{5}{|l|}{ Desire } \\
\hline Low (1.00 - 2.33) & 43 & 17.8 & 3.69 & .404 \\
\hline Medium (2.34 - 3.66) & 121 & 50.0 & & \\
\hline High (3.67 - 5.00) & 78 & 32.2 & & \\
\hline \multicolumn{5}{|l|}{ Conflict } \\
\hline Low (1.00 - 2.33) & 116 & 47.9 & 3.67 & .311 \\
\hline Medium (2.34 - 3.66) & 112 & 46.3 & & \\
\hline High (3.67 - 5.00) & 14 & 5.8 & & \\
\hline \multicolumn{5}{|l|}{ Social Pressure } \\
\hline Low (1.00 - 2.33) & 38 & 15.7 & 3.68 & .401 \\
\hline Medium (2.34 - 3.66) & 163 & 67.4 & & \\
\hline High (3.67 - 5.00) & 41 & 16.9 & & \\
\hline \multicolumn{5}{|l|}{ Peer Presure } \\
\hline Low (1.00 - 2.33) & 28 & 11.6 & 3.73 & .377 \\
\hline Medium (2.34 - 3.66) & 174 & 71.9 & & \\
\hline High (3.67 - 5.00) & 40 & 16.5 & & \\
\hline
\end{tabular}

The table 6 shows the frequency distribution on the eight aspects of the inclination to relapse as answered by the respondents. The descriptive analysis results show the mean score for uncomfortable physical situation as the highest compared to other score means, at 3.81 
with a standard deviation of .392. 52 of the studied respondents (21.5\%) have a low uncomfortable physical level. 138 respondents (57\%) are at a medium level, while the remaining 52 respondents $(21.5 \%)$ are at a high level. This means when they face uncomfortable physical situations, they return to drugs to prevent feeling physical pain, thus increasing the inclination to relapse. Next, for the comfortable emotion aspect, the mean score is 3.74 with a standard deviation of .379 .29 of the studied respondents (12\%) are at a low level of comfortable emotion. 168 respondents (69.4\%) are at a medium level, and the remaining 45 respondents (18.6\%) are at a high level. When analysing the peer pressure dimension, the total mean score is 3.73, with a standard deviation of .377 .28 of the studied respondents (11.6\%) are at a low level. 174 respondents $(71.9 \%)$ are at a medium level, while the remaining 40 respondents (16.5\%) are at a high level. Overall, the results show the peer pressure aspect is at a high level. Next, the negative emotion aspect. The total mean score for negative emotion is 3.70 with a standard deviation of .303. 53 of the studied respondents $(21.9 \%)$ are at a low level of negative emotion. 136 respondents $(56.2 \%)$ are at a medium level, while the remaining 53 respondents (21.9\%) are at a high level.

Furthermore, for the self-control aspect, the total mean score is 3.70 with a standard deviation of .387 .40 respondents (16.5\%) are at a low level for self-control. 131 respondents $(54.1 \%)$ are at a medium level, while the remaining 71 respondents $(29.4 \%)$ are at a high level. Also based on the results, the findings show the mean score for the desire for drugs dimension is 3.69 with a standard deviation of .404 .121 respondents $(50 \%)$ have a medium level towards the inclination to relapse. 78 respondents $(32.2 \%)$ are at a high level for the inclination to relapse, while the remaining 43 respondents (17.8\%) are at a low level. Overall, the study shows the level for inclination to relapse for the desire for drugs aspect to be high. The total mean score for the social pressure aspect is 3.68 with a standard deviation of .401 .38 respondents (15.7\%) have a low level for social pressure. 163 respondents $(67.4 \%)$ are at a medium level, while the remaining 41 respondents $(16.9 \%)$ are at a high level. The final dimension, conflict with others, has a total mean score of 3.67 with a standard deviation of .311 .14 respondents $(5.8 \%)$ are at a low level. 112 respondents $(46.3 \%)$ are at a medium level, while the remaining 116 respondents $(46.3 \%)$ are at a high level. Overall, there is no noticeable mean difference among the eight dimensions for the inclination to relapse, and all means are recorded around 3.81-3.65. The results found almost half of the respondents have a high inclination to relapse for all studied aspects.

\section{Discussion}

The findings show the respondents' negative emotions are at a high level. This might be caused by their emotional distress such as pressure, sadness, depression, anxiety, restlessness, anger, confusion, and guilt. The same issue is related in previous studies on negative emotions, which found anxiety and apprehension as stimuli that increases the inclination to relapse. This can be seen when drug addicts are in a stressful and anxious situation, causing them to lose self-control and affect their behaviour. This means, negative emotions are introduced to the individual with emotion-transforming stimuli or situations. Negative emotions also stimulate relapse behaviour as they influence physical problems within the addict. Addicts require follow-up treatment and emotional management to ensure they can respond property to desires to reuse drugs. For the comforting emotion aspect, studies show respondents are at a medium level. This comforting emotion is said to give positive feelings to addicts, thus increasing the desire for drugs. This then exposes drug addicts to increased risk of relapse (National Institutes on Drug Abuse, 2005). Peer pressure 
refers to stress when respondents meet their old drug-using friends, and have a good time with them, which lead to addicts' inclination to relapse to recapture previously-felt enjoyment. This discovery is in line with the study by by McKay, Alterman, McLellan, \& Snider, (1994), which shows addicts that spend time with their addict friends are more at risk of relapse. They are put in the difficult position to refuse when offered drugs. Relapse is also a continuation of the spectre of addiction all patients suffer from. Provided the access to drugs, they find it difficult to let go, even as they have undergone holistic rehabilitation.

In addition, results show the level of inclination to relapse from a self-control aspect is high. Hirschi (1969) believes everyone has the inclination towards crime if they lack selfcontrol. This means lack of self-control affects the addicts' ability to choose the right decision (Liddle \& Rowe, 2011). The level of inclination to relapse for desire for drugs is at a high level. The desire for drugs refers to the situation when respondents are in a location where they used to obtain drugs, triggering their memory of previous drug abuse. This then leads them to re-use drugs, and then feel it's best for them to remain an addict. The desire for drugs then causes them to repeat the habit. This situation is a challenge to former addicts to prevent them from continuing to use drugs. Next is the social pressure aspect. Social pressure refers to situations when respondents face stress from their environment, causing the inclination to relapse. Social pressure also covers societal stigma towards former addicts, considers as "bad people" and bringer of social ills, leading addicts to isolate themselves. The findings of earlier studies such as Dubey and Agarwal (2007), found social pressure leads to stimuli and exposure to drug use, due to the mental pressure to re-use. This then becomes an important factor that leads former addicts to high rates of relapse. The final dimension is conflict with others. Results show respondents that have conflict or problems with people in their environment hinders their connection to others, leading to the inclination to relapse (Marlatt \& Gordon, 1985).

\section{Conclusion}

In conclusion the results found virtually every respondent reported having the inclination to relapse at the highest level for eight high-risk situations to relapse: negative emotions, physical discomfort, positive emotion, lack of self-control, desire for drugs, conflict, social pressure, and peer pressure. Therefore, this problem of inclination to relapse deserves further study, so the responsible parties can eradicate drug addiction as the largest problem in this country. The findings support the reality as proven by the cognitive and behavioural problem, which states the inclination to relapse as a complex process, arising from a number of highOrisk situations that could influence one's behaviour. It begins with a high-risk situation as a response to expectations, urges, circumstances that trigger their desires, skills development, and self-control. Without the ability to face a high-risk situation, it could potentially lead to relapse. This is based on their ability to identify their own ability to face high-risk situation, skills to overcome stress, and develop positive expectation. They should be helped and fully rehabilitated so they develop courage and internal strength to avoid relapsing into addiction. This means serious and continuous efforts are necessary to rebuild the former addicts' self-confidence, already at a low-level, and allow them to feel stronger when facing life challenges after the end of treatment and rehabilitation. This study supports the theory and model of Marlatt and Gordon (1985) who say the tendency to relapse become increasingly difficult former drug addicts find it difficult to use themselves they are in a depressed situation. From a practical aspect, various types of desirables include behaviours that can change the psychological integration of drug addicts to users to manage stress and 
problems directly. Those who are trained to say no to drugs, hate drugs, find other avenues other than continuing to commit on drugs, need a strong self -defence against drugs, manage all stress without drugs and so on.

\section{References}

Annis, H. M., \& Martin, G. (1985). Inventory of Drug-Taking Situations. Toronto: Addiction Research Foundation.

Basson, N. (2008). The influence of psychosocial factors on the subjective well being of adolescents. Dissertation submitted in accordance with requirements for the degree of Magister Societatis Scientiae (Psychology) in the Faculty of Humanities Department of Psychology. University of the Free State Bloemfontein.

Dennis, M. L., \& Foss, M. A. (2005). Utilizing recovery management checkups to shorten the cycle of relapse, treatment reentry and recovery. Drug and Alcohol Dependence,78(3),325-338. doi:10.1016/j.drugalcdep.2004.12.005

Dubey, A., \& Agarwal, A. (2007). Coping Strategies and Life Satisfaction: Chronically III Patients' Perspectives. Journal of the Indian Academy of Applied Psychology,33,(2),161-168.

Gottfredson, M., \& Hirschi, T. (1986). The value of lambda would appear to be zero: An essay on career criminals, criminal careers, selective incapacitation, cohort studies, and related topics. Criminology, 24, 213-234. doi: 10.1111/j.1745-9125.1986.tb01494.x

Hartwell, K. J., Back, S. E., Mc Rae-Clark, A. L., Shaftman, S. R., \& Brady, K. T. (2012). Motives for using: A comparison of prescription opioid, marijuana and cocaine dependent individuals. Addictive Behaviors, 37(4), 373-378. doi: 10.1016/j.addbeh.2011.11.014

Howell, A. N., Leyro, T. M., Hogan, J., Buckner, J. D., \& Zvolensky, M. J. (2010). Anxiety sensitivity, distress tolerance, and discomfort intolerance in relation to coping and conformity motives for alcohol use and alcohol use problems among young adult drinkers. Addiction Behavior,35, 1144-1147. doi:10.1016/j.addbeh.2010.07.003

Hu, M. C., Davies, M., \& Kandel, D. B. (2006). Epidemiology and correlates of daily smoking and nicotine dependence among young adults in the United States. American Journal of Public Health, 96, 299-308. doi: 10.2105/AJPH.2004.057232

Liddle, H., \& Rowe, C. L. (2011). Adolescent substance abuse: Research and clinical advances. New York: Cambridge University Press.

Marlatt, G. A. (1985). Relapse prevention: Theoretical rationale and overview of the model. In G. A. Marlatt \& J. R. Gordon (Eds.), Relapse prevention: Maintenance strategies in the treatment of addictive behaviors (pp. 3-70). New York: Guilford Press.

McKay, J. R., Alterman, A. I., McLellan, A. T., \& Snider, E. (1994). Treatment goals, continuity of care, and outcome in a day hospital substance abuse rehabilitation program. American Journal of Psychiatry, 151, 254-259. doi.org/10.1176/ajp.151.2.254

Muldoon, O. T., \& Lowe, R. D. (2012). Social identity, groups, and post-traumatic stress disorder. Political Psychology, 33, 259-273. doi: 10.1111/j. 1467-9221.2012.00874

National Institutes on Drug Abuse NIDA. (2005). Monitoring the Future: Overview of Key Findings, 2004 (National Institutes of Health, U.S. Department of Health and Human Services, NIH Publication No. 05-5726).

Shafiei, E., Hoseini, A. F., Bibak, A., \& Azmal, M. (2014). High risk situations predicting relapse in self-referred addicts to province substance abuse treatment centers. International Journal High Risk Behavior Addiction, 3(2),163-181. doi: 10.5812/ijhrba.16381 
Skitch, S. A., \& Abela, J. R. Z. (2008). Rumination in response to stress as a common vulnerability factor to depression and substance misuse in adolescence. Journal of Abnormal Child Psychology, 36, 1029-1045. doi: 10.1007/s10802-008-9233-9

Substance Abuse and Mental Health Services Administration, Office of Applied Studies. (2014). The NSDUH Report: Participation in self-help groups for alcohol and illicit drug use. Retrieved May 20, 2020, from

http://www.oas.samhsa.gov/2k8/selfHelp/selfHelp.pdf

Thomas, R., \& Perera, R. (2006) School-based programmes for preventing smoking. Cochrane Database Systematic Reviews,3, University of Oxford, U.K.

Tomczak, V. M. (2010). The impact of emotional intelligence on substance abuse and delinquency in a college sample: The comparison of emotional intelligence traits versus abilities. Retrieved from ProQuest. (UMI 3422981). 